\title{
Evaluation of Cavity Exploration Technology to deal with Ground Subsidence in Urban Area
}

\author{
Dong-Min Kim ${ }^{1, a}$, Dae-Young Lee ${ }^{1, b}$, Yong Baek ${ }^{3, c}$, Woo-Seok Kim ${ }^{4, d}$ \\ ${ }^{1}$ Department of Geotechnical Engineering Research Division, Korea Institute of Civil Engineering \\ and Building, Gyeonggi-Do, 10223, Republic of Korea

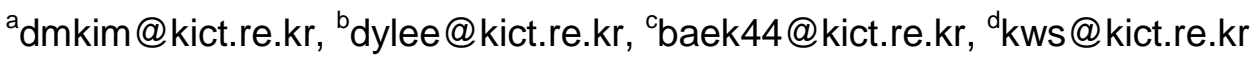

\section{Keywords: Ground Subsidence, GPR, Field test, Cavity, Sewer}

\begin{abstract}
Ground subsidence in downtown is attributable to various factors such as the impact by excavation, soft ground settlement, deteriorated sewer and poor compaction. Road sinking resulting from deteriorated sewer is mostly by the soil penetrated into the damaged sewer. Thus to prevent ground settlement in downtown, it's necessary to develop the detection technique that will evaluate the mechanism and predict the ground settlement by leaked sewer. GPR exploration is used to detect the cavity under the ground but when the cavity is deep or boundary between cavity and loosened soil is unidentified or complicate utilities and cavity and loosened soil are mixed, it's difficult to detect them. This study, as part of the way to prevent ground settlement by deteriorated sewer, was intended to identify the cause of cavity and soil relaxation and evaluate the cavity exploration technique using GPR exploration method. To simulate the cavity and ground relaxation caused by sewer leak, field test was conducted. $450 \mathrm{~mm}$ in diameter and 2,500 $\mathrm{mm}$ long concrete hume pipe was used install the sewer for the test and to evaluate the exploration performance by depth, sewer was buried at $1.0 \mathrm{~m}$ and $1.5 \mathrm{~m}$ depth. After putting the ice seized $1 \mathrm{~m} \times 1.0 \mathrm{~m} \times 0.3 \mathrm{~m}$ on top and at the bottom of the sewer, hose was connected to promote the thawing. To measure the cavity caused by ice thawing, GPR exploration was carried out in a day, 5 days and 15 days. In the result of test, Cavity and ground relaxation caused by sewer leakage were simulated using GPR exploration and the cavity and ground relaxation by sewer leakage were monitored. According to GPR analysis, ice thawing caused ground relaxation and the cavity. Given the reflective surface under the ground over time, cavity appeared to have developed upward. Though ground settlement by cavity was expected, no ground settlement occurred which was attributable to bearing capacity of the well-compacted ground.
\end{abstract}

\section{Introduction}

Development of underground space is put on track amid increasingly saturated urban area and excavation has been performed on the or under the ground in various ways considering neighboring structures [1]. Then careless management, poor technologies, unexpected groundwater or failure of timely response to the change of the soil layer or inappropriate earthwork system has caused the land subsidence problem [1,2]. According to Seoul city office, 2,714 of 3,205 or $84 \%$ of road sinking occurred since 2010 were attributable to deteriorated sewer and of 10,392 km-long sewer, $73.3 \%$ was more than 20 years old, indicating the need for urgent maintenance [3].

To prevent ground settlement in urban area, exploration technique to evaluate the land subsidence mechanism and prediction is necessary [4]. GPR method is used to detect the cavity under the ground surface, which however is difficult to apply when the cavity is in depth, when the boundary between cavity and relaxed zone is unclear or when the complex utilities, cavity and relaxed zone are mixed together [5].

This study, as part of the way to prevent land subsidence by sewer installation, is intended to identify the formation process of cavity and relaxed zone as well as evaluate the technique using GPR method to detect the cavity under the ground surface. Cavity simulation above the sewer was conducted with GPR method through the field test application and the possibility of detecting the 
cavity and relaxed zone under the ground was evaluated.

\section{Test Application of the Cavity under the Ground and GPR Exploration}

Field test was conducted to simulate the cavity and ground relaxation caused by sewer leakage. Sewer used was concrete hume pipe, diameter $450 \mathrm{~mm}$ and length $2,500 \mathrm{~mm}$ and for evaluation by depth, sewer was laid at $1.0 \mathrm{~m}$ and $1.5 \mathrm{~m}$ depth. The ice sized $1 \mathrm{~m} \times 1.0 \mathrm{~m} \times 0.3 \mathrm{~m}$ was placed above and under the sewer, respectively, and to have the ice to be melted quickly, the hose was connected and covering material used was sand and soil and the cavity and ground relaxation caused by ice melting were simulated. To measure the cavity generated by ice melting, GPR exploration was conducted in 1 day, 5 days and 15 days, respectively. GPR equipment used for the study is as described in Table 1. To evaluate the exploration performance depending on frequency, the frequency was changed to $100 \mathrm{MHz}, 300 \mathrm{MHz}, 500 \mathrm{MHz}$ and 1,500 MHz.

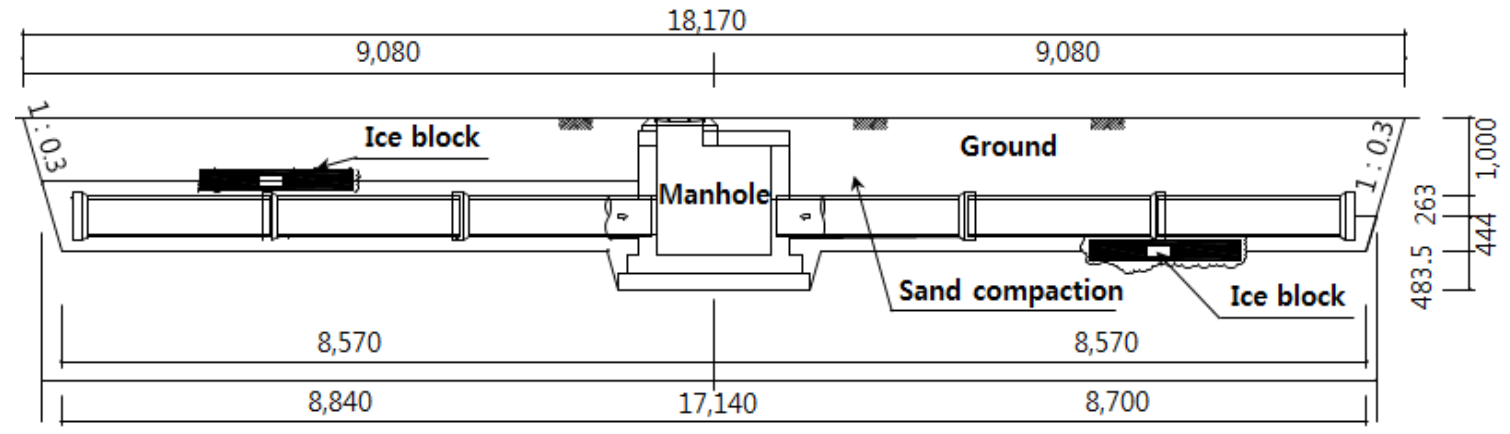

Fig. 1 Installation of the Sewer.

Table 1. Specification of GPR Equipment.

\begin{tabular}{c|l|c}
\hline Category & \multicolumn{1}{|c|}{ Specification } \\
\hline \multirow{6}{*}{ GPR } & - Zond 12e (RADAR Systems, Inc.) & - Shield Antenna (300MHz, 500MHz) \\
& - Notebook P/C & -S/W (Prism 2.5) for analysis
\end{tabular}

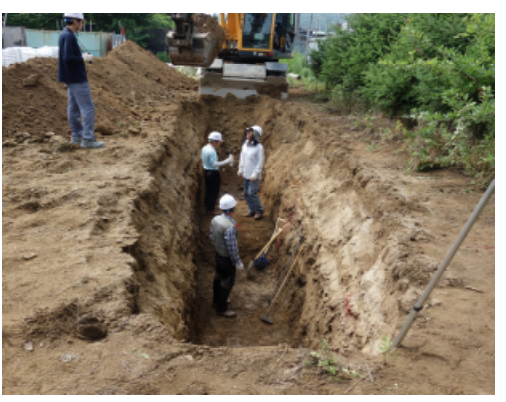

(a) Excavating

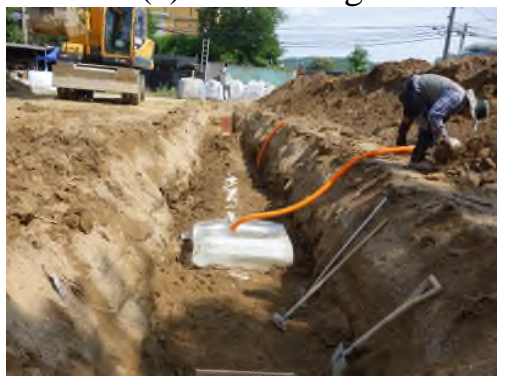

(d) Putting the ice on sewer

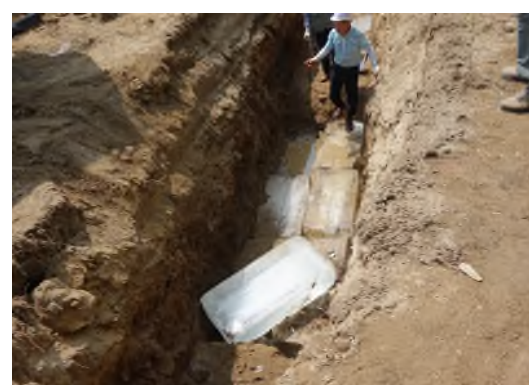

(b) Laying the Ice and sand

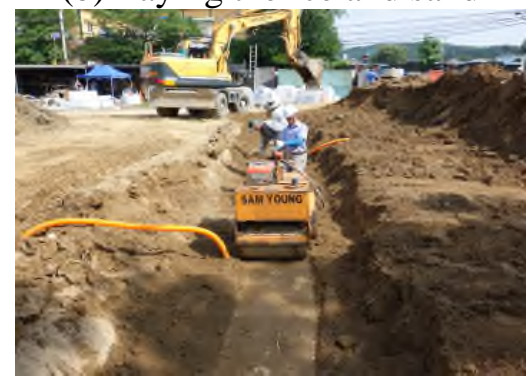

(e) Tamping

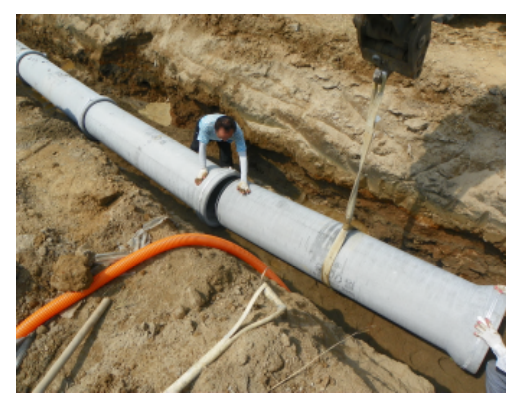

(c) Laying the sewer

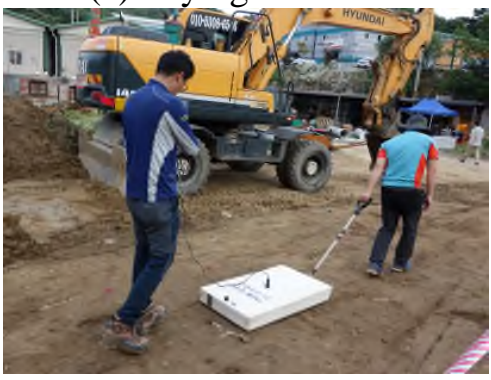

(f) GPR exploration

Fig. 2 Process of the Field Test Application. 


\section{GPR Exploration of the Cavity under the Ground Surface}

Fig. 3 shows analysis of GPR exploration over time. As a result of cavity detection for the sewer with $1.5 \mathrm{~m}$-thick covering soil and the frequency $500 \mathrm{MHz}$, a parabolic reflection plane was distributed above the sewer which appeared to be caused by ice above the sewer. Parabolic reflection plane in a day, 5 days and 15 days appeared at upper level than the level immediately after laying the sewer, indicating the formation of the cavity that might occurred while the ice was melted. According to GPR exploration analysis, the cavity above the sewer was formed when the ice was melted which caused ground relaxation and the cavity over time. Given the reflection plane occurred below the ground surface in 5 days, the cavity was extended upward. As the cavity was formed, ground settlement was expected but not occurred in fact because of the tamping effect. Given no reflection plane was monitored when the ice was placed under the sewer, radar wave appeared not to have penetrated into the sewer.

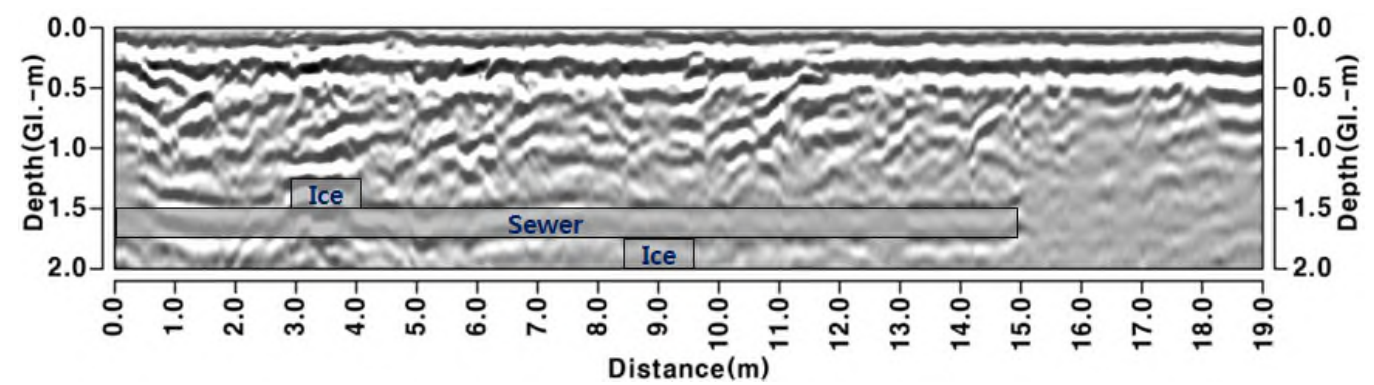

(a) Immediately after installation

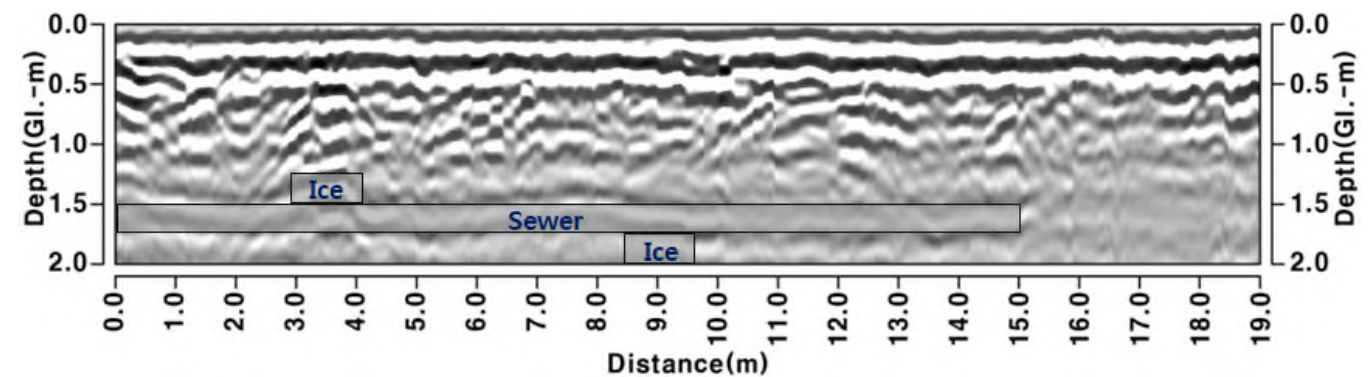

(b) In a day

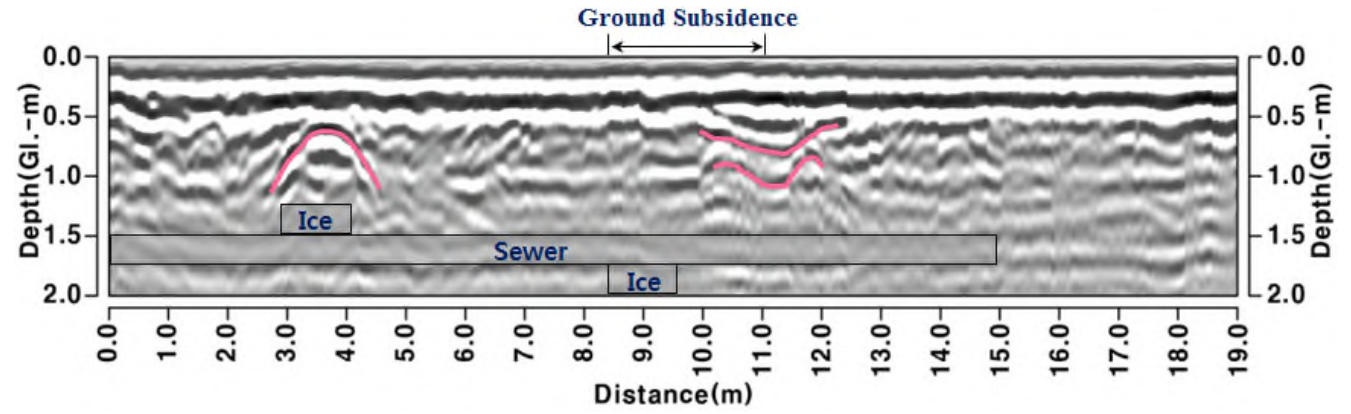

(c) In 5 days

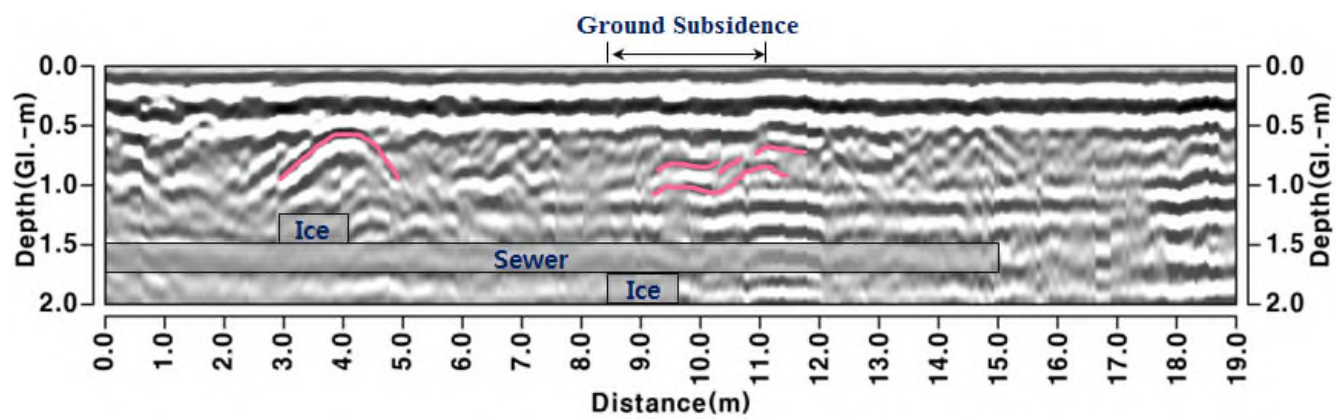

(d) In 15 days

Fig. 3 GPR Analysis Result (500 MHz). 


\section{GPR Exploration Performance depending on Frequency}

Fig. 4 shows exploration result depending on variation of the frequency. No response was monitored at $100 \mathrm{MHz}$, but a slightly curved horizontal reflection plane was extended to $15.0 \mathrm{~m}$ depth along the top of the sewer at $300 \mathrm{MHz}$. Parabolic reflection plane was distributed above the sewer where the ice was placed which was attributable to the cavity formed by ice melting above the sewer. Reflection plane by cavity was monitored at $500 \mathrm{MHz}$, which however disappeared over time, indicating the lower reliability for land subsidence than $300 \mathrm{MHz}$. No reflection plane by the sewer was monitored at $1,500 \mathrm{MHz}$ and the signal considered to be the reflection plane by the cavity appeared to be very weak after the ice had been melted. Generally, the higher the GRP frequency the higher the exploration precision but at the depth $1.0 \mathrm{~m} \sim 1.5 \mathrm{~m}, 500 \mathrm{MHz}$ appeared to have been appropriate.

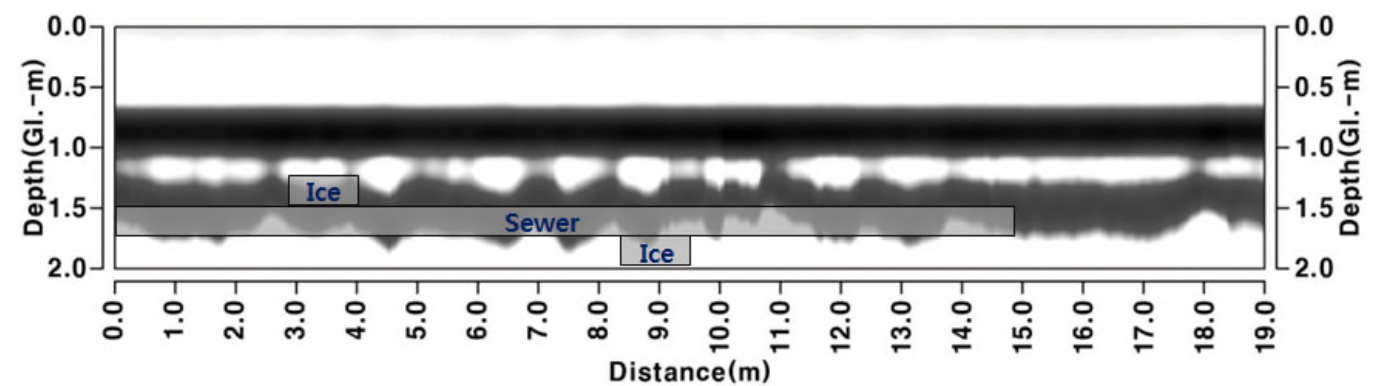

(a) $100 \mathrm{MHz}$

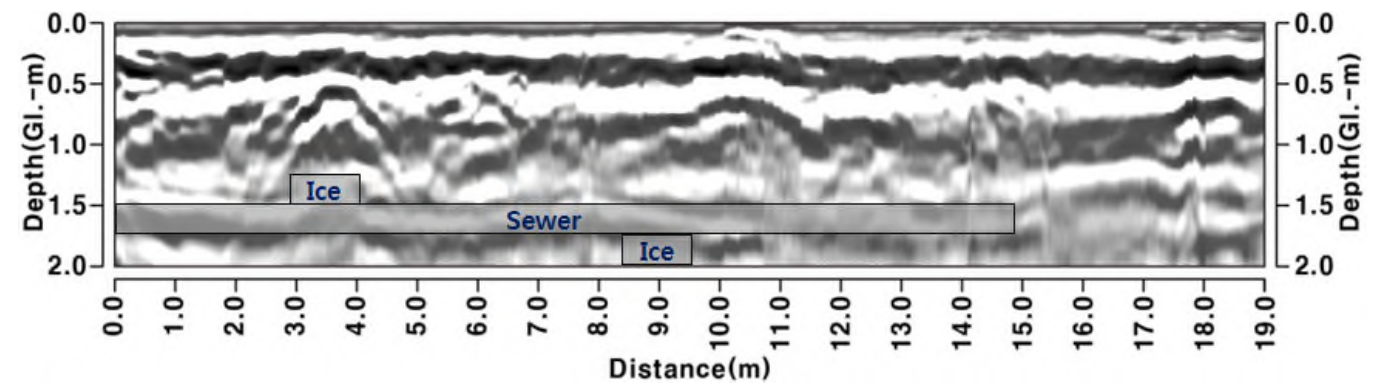

(b) $300 \mathrm{MHz}$

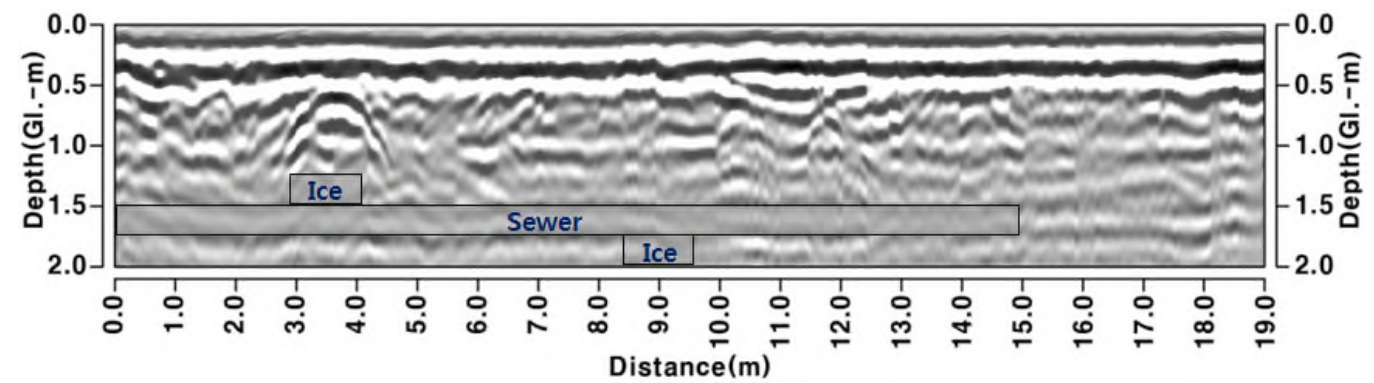

(c) $500 \mathrm{MHz}$

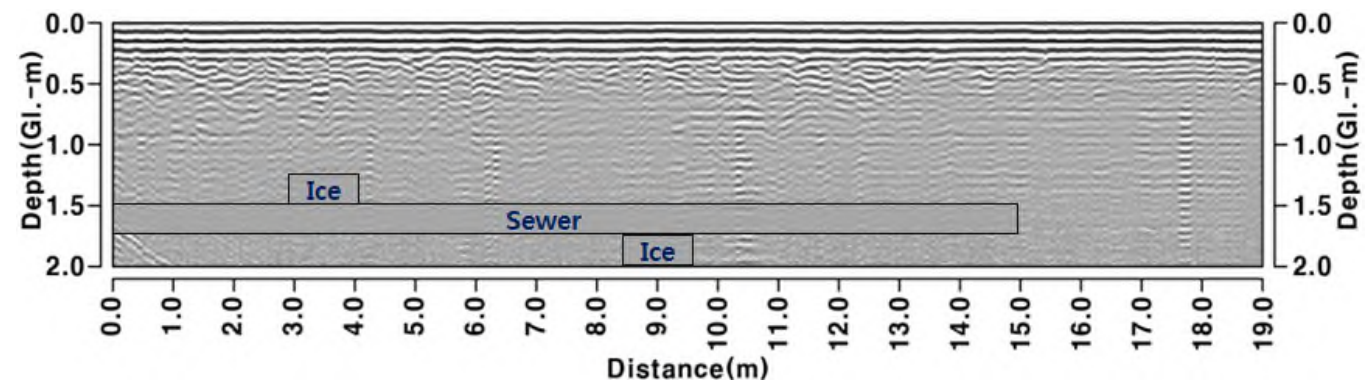

(d) $1,500 \mathrm{MHz}$

Fig. 4 GPR Analysis Result depending on Frequency. 


\section{Conclusions}

Field test application and GPR exploration were conducted to identify the cavity and ground relaxation behavior due to sewer leakage and consequently, conclusion was made as follows.

1. The cavity and ground relaxation due to sewer leakage were simulated through field test which was then monitored by GPR exploration.

2. According to GPR analysis, ground relaxation occurred while ice began melting, causing to form the cavities. Given the reflection plane formed below the ground surface over time, the cavity seemed to extend upward. Though the cavity was formed, no ground surface settlement was monitored which seemed to be attributable to tamping effect.

3. Given no reflection plane was monitored at the location where the ice was placed below the sewer, GPR radar wave appeared not to have penetrated into the sewer.

4. According to GPR exploration, reliability for land subsidence was the highest at $500 \mathrm{MHz}$ and no reflection plane by sewer was monitored at 1,500 MHz. Exploration precision is known to be higher when GPR frequency is higher but according to the study, $500 \mathrm{MHz}$ was appropriate when the depth was at $1.0 \mathrm{~m} \sim 1.5 \mathrm{~m}$.

5. To predict the cavity due to sewer leakage, it's necessary to develop the optimal evaluation method based on determination of frequency depending on depth and the analysis of exploration signal correlations.

\section{Acknowledgement}

This study was successfully performed thanks to the support by construction technology research project (Development of land subsidence and ground stability evaluation and excavation reinforcement technology 15SCIP-B108153-01) of Korea Agency for Infrastructure Technology Advancement, the Ministry of Land, Infrastructure and Transport, for which we extend our deep gratitude.

\section{References}

[1] D. Y. Lee, D. M. Kim, J. I. Oh, J. R. Yoon, A Study on Ground Subsidence Assessment Technique due to Sewer Damage, Proc. Symp. Korean Soc. Civil Eng. (2015), pp. 215-216.

[2] D. Y. Lee, Y. W. Choi, H. Choi, Cavity Detection under Road Structure for Cause Survey of Road Cave-in, Proc. Symp. Korean Soc. Civil Eng. (2015), pp. 217-218.

[3] Road Management Team of Seoul City, Seoul City's Management of Road Sinking and Manual, Special Training Manual for Seoul City Officials, 2015.

[4] J. Y. Kim, S. J. Lee, J. I. Oh, D. Y. Lee, Correlation Analysis of Land Subsidence with Sewer Defect, Proc. Korea Soc. Wastewater Conf. (2015), pp. 643-644.

[5] J. J. Park, J. G. Han, S. K. Yoo, K. K. Hong, GPR Technology for Cavity Exploration, J. Korean Geosynth. Soc. 14(3) (2015) 12-17. 